\title{
Characteristics of Lithium-Manganese Ferrite as Magnetic Carrier for Electrophotography
}

\author{
M.OCHIAI, M.ASANAE ${ }^{1}$ and T.IIMURA ${ }^{2}$ \\ 1) Magnet div. Kumagaya Works, Hitachi Metals,Ld. \\ 5200 Mikajiri, Kumagaya, Saitama 360, Japan \\ 2) Hitachi Metals Technox,Ltd. \\ 3-7-1 Nishisinjuku, Shinjuku Tokyo 163-10, Japan
}

\begin{abstract}
Characteristics of the Lithium-Manganese ferrite were investigated to use as a magnetic carrier for electrophotography. The Lithium-Manganese ferrite system has no hazardous heavy metal which gives bad effects to nature as industrial waste after use. The Lithium-Manganese ferrite carrier was prepared by atomizer granulation and normal air sintering process. In the several limited compositions, the lithium-manganese ferrite had sufficient magnetization for electrophotography. Grain size of the carrier surface was increased by increasing sintering temperature. So, carrier surface could be controlled from rough to smooth by changing the sintering temperature. And regulation of electrical resistivity of the carrier was obtained by annealing in the nitrogen atmosphere. Chargeability of the lithium-manganese ferrite carrier was influenced by its composition, and stable tribolectric charge was obtained through the agitation time for mixing with toner.
\end{abstract}

\section{INTRODUCTION}

An electrophotographic copier and a printer are roughly divided into mono-component and double-component system. In the former system only magnetic or nonmagnetic toner is used, magnetic materials such as a iron or ferrite and toner are used in the latter system.

As a carrier, iron powder was used before, but ferrite with long developer lifetime became general because of the smaller specific gravity[1]. Ferrite carrier has been used for electrophotography as a developer mixture with toner to forming the magnetic brush and to develop the latent image on the photoconductor. Ferrite carrier is a spherical beads mean particle size from 40 to 100 micro meter which consists of the soft ferrite material of $\mathrm{Ni}-\mathrm{Zn}$ or $\mathrm{Cu}-\mathrm{Zn}$ etc.[2]. The characteristics which we needs to the ferrite carrier is higher magnetization, certain range of electrical resistivity and chargeability in addition to the particle size and the distribution.

Recently, according to the State of California rejection regulation TITLE 22 div. 4 "Environmental Health" in USA, there is a fear for the ferrite carrier containing heavy metals against to this regulation when disposing. In this study, we investigated the characteristics of the lithium-manganese ferrite system as a magnetic carrier for electrophotography which containing only harmless metals comparing to the regulation[3].

\section{EXPERIMENTAL}

The samples used for this experiment were prepared as following procedure. Raw materials of $\mathrm{Li}_{2} \mathrm{CO}_{3}, \mathrm{MnCO}_{3}$ and $\mathrm{Fe}_{2} \mathrm{O}_{3}$ were weighed to become fixed composition and mixed by dry process. It was presintered for $5 \mathrm{~h}$ at $950^{\circ} \mathrm{C}$. Presintered powder was milled by wet process to the size of submicron, then polyvinylalcohol was added as a binder.
The sample was granulated by a spray dryer to around 60 micron and sintered it in air for $2 \mathrm{~h}$ at the temperature between $1160^{\circ} \mathrm{C}$ and $1320^{\circ} \mathrm{C}$. The sintered powder was classified to the distribution range $37-105 \mu \mathrm{m}$. The obtained sample was examined its magnetic property and electrical resistivity as a ferrite carrier. The magnetic properties were measured by vibrating sample magnetmeter(VSM). Electrical resistivity of the carrier was measured by a two point contact method. The chargeability of the carrier was examined by measuring the triboelectric charge of the mixture of each carrier and standard toner by blow-off method(Toshiba chemical, co.Ltd,TB-200).

\section{RESULTS AND DISCUSSION}

Table 1 shows several composition of the ferrite system. By these composition ferrite carrier was obtained using above-mentioned procedure. Relationship between the sintering temperature of the ferrite system listed Table 1 and the magnetization is shown in Figure 1. The composition F$1\left(\mathrm{MnFe}_{2} \mathrm{O}_{4}\right)$ showed small magnetization at higher sintering temperature. Usually, Manganese ferrite was sintered in nitrogen atmosphere, but it gave too low resistivity to use as a carrier. Then, F-1 composition was tried to sinter in air. Xray diffraction pattern of the F-1 showed only hematite peak, and suggests no Manganese ferrite. These results showed that sintering Manganese ferrite needs deoxidization atmosphere, and Manganese ferrite was oxidized by sintering in air. Composition F-2, F-4 and F-5 were Li-Mn ferrite system gave higher magnetization in the certain range of the sintering temperature. In these composition F-5 showed higher magnetization value close to $\mathrm{Cu}-\mathrm{Zn}$ ferrite and enough to be used as carrier for electrophotography.

F-2 has less amount of Lithium gave lower magnetization than other $\mathrm{Li}-\mathrm{Mn}$ ferrite. $\mathrm{F}-3\left(\mathrm{Li}_{0.5} \mathrm{Fe}_{25} \mathrm{O}_{4}\right)$ is Lithium ferrite, showed higher magnetization at lower 
sintering temperature but magnetization was extinguished with higher sintering temperature. Figure 2 shows photographs of the free surface of carrier of F -5 with various sintering temperature. The grain size of the carrier surface increased and the surface was changed from rough to smooth with increasing the sintering temperature. $\mathrm{X}$-ray diffraction pattern of the $F-5$ is shown in Figure 3. This pattern showed singlephase of the Li-Mn ferrite. Figure 4 also shows a temperature dependency of magnetization of F-5 ferrite carrier. Li-Mn ferrite showed high Currie temperature $\left(\mathrm{Tc}=547^{\circ} \mathrm{C}\right)$.

Electrical resistivity is also one of the important characteristics of ferrite carrier. Electrophotography needs carrier with certain range of electrical resistivity. Carrier is used to form magnetic brush with toner by magnetic force on the magnetic roller, and added bias voltage to the developing site through the carrier chain from magnetic roller. So carrier needs electrical resistivity the range of $10^{5}$ $\sim 10^{10} \Omega \cdot \mathrm{cm}$. Electrical resistivity of the $\mathrm{Li}-\mathrm{Mn}$ and $\mathrm{Cu}-\mathrm{Zn}$ ferrite in the various electric field were shown in Figure 5. $\mathrm{Li}-\mathrm{Mn}$ ferrite showed higher electrical resistivity than $\mathrm{Cu}-\mathrm{Zn}$ ferrite in the measured region. The carrier with relatively high resistivity cannot add enough bias voltage. We tried to decrease the electrical resistivity of Li-Mn ferrite carrier. By annealing treatment at $800 \sim 1000^{\circ} \mathrm{C}$ for $2 \mathrm{~h}$ in a nitrogen atmosphere lower electrical resistivity were obtained. Annealing in air occurs reduction of the magnetization additional to the lower resistivity. In this way Li-Mn ferrite had become close electrical property to $\mathrm{Cu}-\mathrm{Zn}$ ferrite.

Chargeability is also important property for carrier. It is difficult to measure the chargeability of carrier directly, so we measured a triboelectric charge of the mixture of each carrier and standard toner with blow-off method. Figure 6 shows changes of the toriboelectric charge of the carriers during the agitation time of blender. Relatively stable triboelectric charge was obtained by $\mathrm{Li}-\mathrm{Mn}$ carrier. It will be considered chargeability of carrier was naturally decided by composition and surface property. The cause of changes for triboelectric charge is not clear, but lesser changes could be desirable for electrophotographic print system.

Table 1 Composition of ferrite systems for ferrite carrier

\begin{tabular}{cccc}
\hline (mol\%) & $\mathrm{Li}_{2} \mathrm{CO}_{3}$ & $\mathrm{MnCO}_{3}$ & $\mathrm{Fe}_{2} \mathrm{O}_{3}$ \\
\hline $\mathrm{F}-1$ & & 53 & 47 \\
\hline $\mathrm{F}-2$ & 5 & 35 & 60 \\
\hline $\mathrm{F}-3$ & 17 & & 83 \\
\hline $\mathrm{F}-4$ & 15 & 25 & 60 \\
\hline $\mathrm{F}-5$ & 10 & 20 & 70 \\
\hline
\end{tabular}

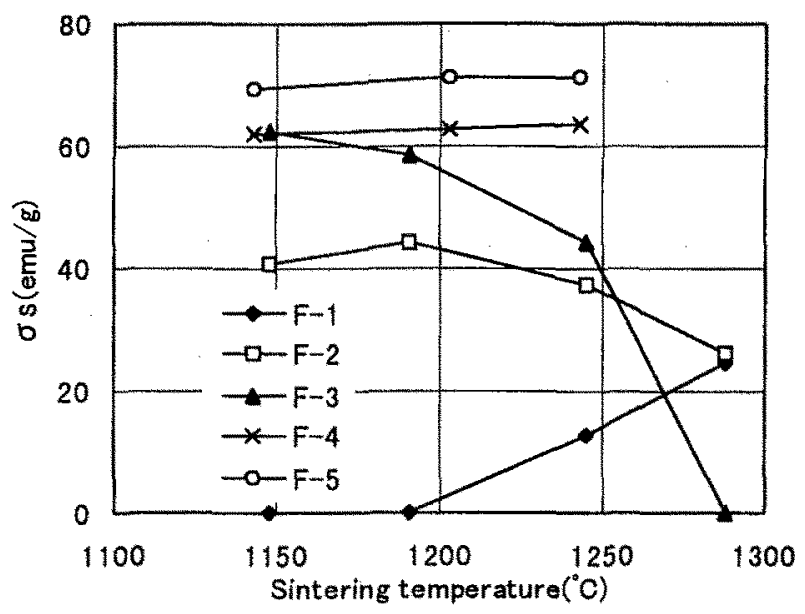

Fig.1 Magnetization of lithium-manganese ferrite system with various composition and sintering temperature.
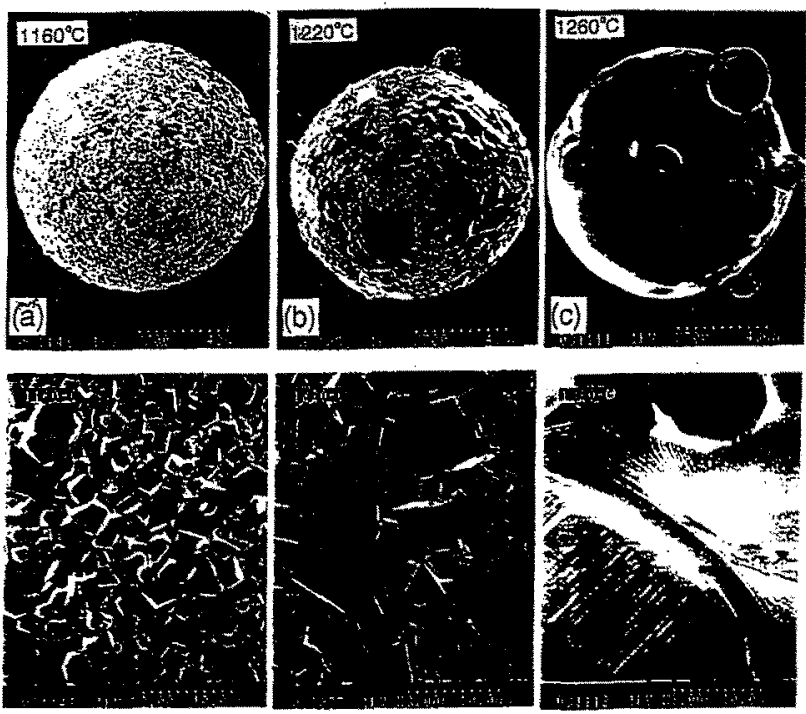

Fig.2 Free surface of Li-Mn ferrite carrier.

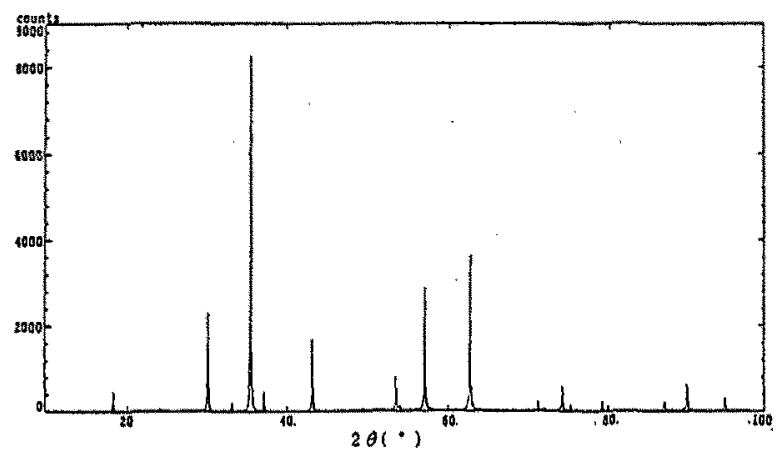

Fig. 3 X-ray diffraction pattern of Li-Mn ferrite carrier. (sintered at $1260^{\circ} \mathrm{C}$ ) 


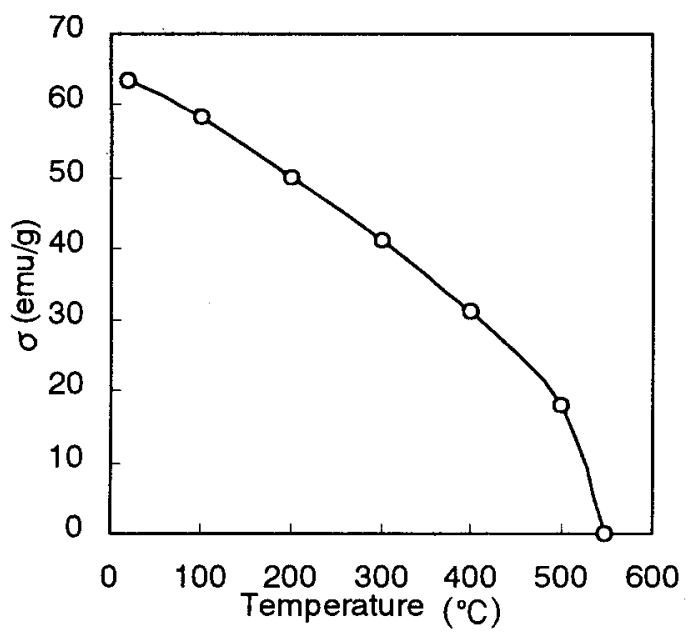

Fig. 4 Magnetization-temperature dependency of Li-Mn ferrite.

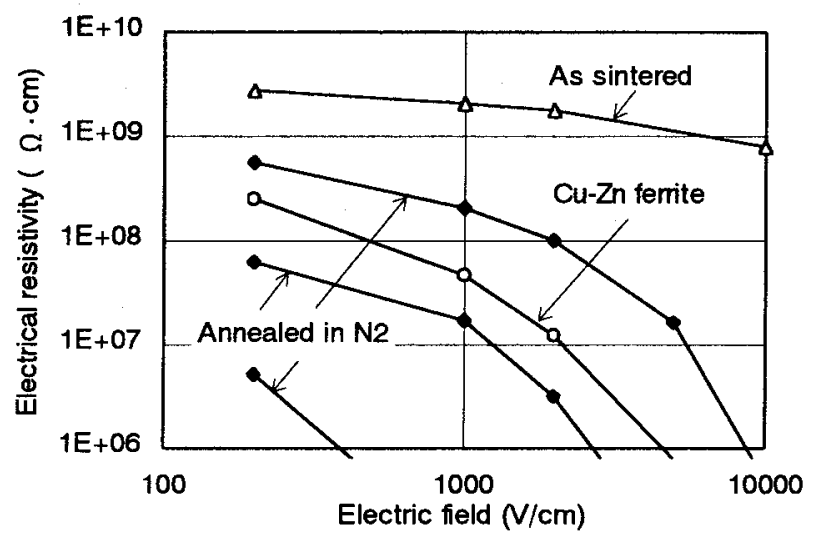

Fig.5 Electric field dependency of electrical resistivity of the Li$\mathrm{Mn}$ and $\mathrm{Cu}-\mathrm{Zn}$ ferrite carrier.

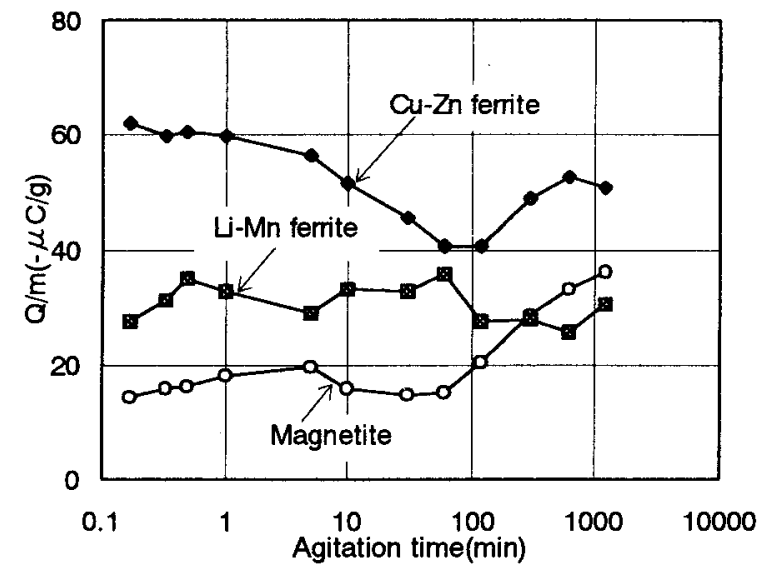

Fig.6 Changes of the triboelectric charge of carriers.

\section{REFERENCES}

[1] T.Iimura, K.Eguchi and H.Harada, IEEE Trans. Magn., MAG-19, pp1781, 1983.

[2] H.Harada, T.Iiimura and K.Eguchi, IEEE Trans. Mag. Vol. CHMT-9[2], pp202, 1986.

[3] T.Iimura, M.Ochiai and T.Saito, Digests of Powder and Powder Metallurgy (Kyoto Inst. Tech., May27-29, Kyoto) pp272, 1997. 